\title{
Wellbeing index avoiding scaling and weights
}

\author{
Índice de bienestar evitando \\ escalado y ponderaciones
}

http://dx.doi.org/10.17981/cultedusoc.12.2.2021.11

Recibido: 17 de octubre de 2020 Aceptado: 28 de enero de 2021 Publicado: 1 de julio de 2021

\author{
Satyendra Nath Chakrabartty \\ Indian Ports Association, Indian Maritime University (India) \\ chakrabarttysatyendra3139@gmail.com
}

Para citar este artículo:

Chakrabartty, S. N. (2021). Wellbeing index avoiding scaling and weights. Cultura, Educación y Sociedad, 12(2), 181-204. DOI: http://dx.doi.org/10.17981/cultedusoc.12.2.2021.11

\section{Abstract}

Existing well-being measures differ in terms of number and format of items, factors being measured, aggregation methods, and are not comparable. A well-being measure involves combining n- number of indicators and quality of the measure depends on properties of combining procedures adopted. The paper proposes two assumption-free aggregation methods to satisfy the desired properties of an index The paper proposes two indices of well-being in terms of cosine similarity and Geometric Mean (GM) avoiding problems associated with scaling of raw data and choosing of weights. Empirical illustration is provided on application of the proposed measures. The proposed indices give better admissibility of operations and satisfy properties like time-reversal test, formation of chain indices, computation of group mean and statistical tests for comparison across time and space. The preferred index can be constructed even for skewed longitudinal data and helps to reflect path of improvement registered by a country/region over time. The index based on GM is preferred due to wider application areas. The index can further be used for classification of countries, sub-groups and even individuals with morbidity in terms of overall wellbeing values. Future studies suggested.

Keywords: Wellbeing index; geometric mean; time reversal test; chain indices

JEL classification: I31, D60, D63, O15

\section{Resumen}

Las medidas de bienestar existentes difieren en términos de número y formato de elementos, factores que se miden, métodos de agregación y no son comparables. Una medida de bienestar implica combinar un número $\mathrm{n}$ de indicadores y la calidad de la medida depende de las propiedades de los procedimientos de combinación adoptados. El artículo propone dos métodos de agregación sin supuestos para satisfacer las propiedades deseadas de un índice en términos de similitud de coseno y Media Geométrica (GM), evitando problemas asociados con el escalado de datos brutos y la elección de pesos. Se proporciona una ilustración empírica sobre la aplicación de las medidas propuestas. Los índices propuestos brindan una mejor admisibilidad de las operaciones y satisfacen propiedades como la prueba de inversión del tiempo, la formación de índices en cadena, el cálculo de la media del grupo y las pruebas estadísticas para la comparación en el tiempo y el espacio. El índice preferido se puede construir incluso para datos longitudinales asimétricos y ayuda a reflejar la trayectoria de mejora registrada por un país/región a lo largo del tiempo. Se prefiere el índice basado en GM debido a áreas de aplicación más amplias. El índice se puede utilizar además para clasificar países, subgrupos e incluso personas con morbilidad en términos de valores generales de bienestar. Se sugieren estudios futuros.

Palabras clave: Índice de bienestar; significado geométrico; prueba de inversión de tiempo; índices de cadena 
Wellbeing Index (WBI) attempts to assess in quantitative terms - how people are doing. A wellbeing measure is a Composite Index (CI) combining measures of multidimensional aspects of wellbeing such as economy, physical health, psychological wellbeing, environment, social/cultural capital, satisfaction of basic needs, time use, etc. Separate indices developed for each such area. An individual indicator like poverty, gender bias, psychological wellbeing, etc. could be multidimensional consisting of several indices. WBI selects broader areas called drivers or domains or dimensions, followed by selection of indicators for each such domain. Thus, measurement of dimension/domain scores and associated aggregation methods need special attention. Social and psychological data are usually ordinal and discrete. Combining such data with continuous data in interval/ratio scale is problematic. Major uses of WBI are (i) comparisons among persons or countries/regions/societies across time and space (ii) ranking and classifying the units (iii) identifying contribution of each domain/indicator to WBI (iv) identifying critical areas for policy changes towards individual and societal goals (v) drawing path of improvement of WBI over time for a unit and making inter-country or inter-regional comparisons with respect to such paths (vi) computing mean WBI for a group of units (Global WBI). Thus, methodologically sound WBI is needed to facilitate all such uses.

WBI involves choosing appropriately a real valued function $f$ from $n$-dimensional real space corresponding to $n$-number of indicators. Quality of WBI depends on properties of such function and measurement procedures adopted for the constituent indicators. Methods used, number and format of items, factors being measured, etc. are different for different WBIs. Absence of agreed determinants of wellbeing has given rises to controversies and criticisms (Sharpe, 2004). Objective Wellbeing (OWB) measures generally use indicators related to education, physical, environment, community, and economy and tend to capture societal aspects rather than an individual perspective on wellbeing. Examples of OWBs are:

- Canadian Index of Wellbeing (Michalos et al., 2011).

- Wellbeing in Gallup surveys (Rath \& Harter, 2014).

- Wellbeing in the UK (Stiglitz, Sen \& Fitoussi, 2009).

- New Economic Foundation (Bailey, 2016).

Subjective Wellbeing (SWB) measures with number of sub-dimensions consider individual's subjective assessment, primarily based on cognitive judgments and affective reactions and includes psychological, social, and spiritual aspects of wellbeing (Cooke, Melchert \& Connor, 2016; Linton, Dieppe \& Medina-Lara, 2016). A WBI may use both OWB and SWB measures. Researchers used different indicators and methods for transferring raw data for normalization and aggregation for WBI. There is no universally accepted measure (Layard, 2010). Problems at stages of construction of WBI limit usefulness of WBI to make meaningful comparison of units over time and, assessment of contribution 
of indicators/domains, along with direction of developments (Saisana \& Tarantola, 2002). Need is felt to review major issues at various stages of construction of WBI and suggest method to have WBI avoiding problems associated with scaling and choosing weights. The aggregation method to satisfy the desired properties including computation of WBI for a group of countries.

Rest of the paper is organized as follows. Major limitations of WBI along with suggested remedies are discussed in the following section. This is followed by the proposed methods in terms of angular similarity and geometric mean of ratios of current and base period values for each indicator and their properties. The paper is rounded up in by recalling the salient outcomes and emerging suggestions.

\section{LiterATURE REVIEW}

\section{Major Limitations of WBIs}

\section{- Nature of data and Non- admissibility of operations}

Threshold-based classification rules for scoring indicator decides threshold values arbitrarily, violating general statistical principle for classification and may fail to reflect differences meaningfully. Small change in threshold value can significantly change organizational performance (Jacobs, Smith \& Goddard, 2004). Through simulation, Venkatesh and Bernheim (2016) found that about one-third of US Hospitals may change CMS Star Rating from year-to-year basis due to chance alone. National Accounts of Well-Being-NAWB (OECD, 2008) transforms standardized score to $0-10$ so that average score for Europe is always 5.

Ordinal and discrete values obtained through survey using Likert scales are not equidistant and items are not equally important as inter-item correlations, item-total correlations and factor loadings are different for the items. Moreover, the subjects do not perceive successive levels of Likert items as equidistant (Lee \& Soutar, 2010). Thus, adding/averaging may not be meaningful (Bastien, Vallieres \& Morin, 2001). Cronbach's alpha is not possible for single Likert item scale like Overall Life Satisfaction (OLS) (International Wellbeing Group, 2013). Such scales give small number of points of discrimination. The SF-36, for measuring health status consists of 36-Likert items with different number of response categories, transforms raw scores to [0 - 100] by equation (1) (Ware \& Sherbourne, 1992). Here, minimum possible raw score will vary across the sections due to different number of response categories. Mean, Standard deviation (SD) and shape of distribution are different for 4-point, 5-point, 7-point Likert scales. Mean and variance increase with increase in number of levels (Finn, 1972). The estimated mean is more influenced by number of levels than the underlying variable (Lim, 2008). 
Reliability, validity, and discriminating power are different for $K$-point scales for $K=4$, 5, 6, 7 and so on (Preston \& Colman, 2000). Personal Wellbeing Index (PWI) (Cummins, Eckersley, Pallant, Van Vugt \& Misajon, 2003) is a self- reported questionnaire with seven Likert items of satisfaction, each with 11 response categories marked as $0,1,2, \ldots, 10$. The eighth item on 'spirituality or religion' may be non-relevant. The raw scores are converted to $[0,100]$ and converted scores are added, assuming admissibility of addition and equal importance to the items - both are not justified. The Social Progress Index (SPI) has over 50 indicators including one in ordinal scale (drinking water violation) with score range $[0,6]$. Summative scores of Likert data need to be transformed to interval/ratio scale for combining with ratio scale data. Averaging of percentages give wrong results, if the denominators are different or not multiple of the other. Similarly, Actual value (in \%) - Minimum value (in \%) could be problematic. However, division of two figures in percentages is admissible. Human Poverty Index (HPI) (United Nations Development Programme-UNDP, 2007) considers cubic root and 4-th root of average of figures in percentage for HPI-1 and HPI-2 respectively.

Summative score of Happiness survey involving positive and negative components of happiness suffers from substitution effect since a low value of positive component may be nullified by a higher value of negative component. Many WBI involves positive indicators (higher value $\Rightarrow$ higher WBI) as well as negative indicators (Lower value $\Rightarrow$ higher WBI). Aggregating such positive and negative indicators need prior adjustment.

\section{- Suggestions}

a. For Likert items with equal number of response categories, transformation to ratio scale proposed by Chakrabartty (2019) may be adopted to get continuous, monotonic, equidistant scores avoiding ties.

b. For Likert items with different number of response categories, Chakrabartty (2020) provided transformations where scores of subtests with $K$-point items $(K=3,4,5,6)$ are normally distributed with same mean and variance, which can be added to attain comparable results.

\section{Zero anchor value in Likert items}

Often, zero is attached to a level of Likert items (like PWI, SPI, HPI, etc.) which distorts mean, SD, skew, kurtosis of scale. Too many zero responses to an item will lower covariance and correlation with that item. Remedial action is to avoid zero as an anchor value and use numbers $1-5$ to the levels.

\section{- Relative importance of the indicators}

The indicators may contribute differently to WBI. Thus, relative importance of the indicators in WBI needs to be assessed efficiently. Different distributions of the indicators and WBI, different correlation between an indicator and WBI, may not reflect proper contribution of the indicator to WBI. 


\section{- Suggestion}

Construct WBI so that it is easy to quantify contribution of an indicator to the WBI and rank the indicators accordingly. Defining WBI as Geometric mean (GM) of ratios of current and base period values of chosen indicators may avoid complicated calculation and interpretation of correlation ratio (non-linear data associations) with WBI and its decomposition suggested by Becker, Saisana, Paruolo \& Vandecasteele (2017).

\section{Path of improvement}

WBI of a country can be looked as an impact of the policy decisions and use of resources. However, existing WBIs fail to facilitate assessment of well-defined improvement of overall progress/decline registered by a country from the base period and drawing the path of improvement of the WBI. For CI covering morbidity issues, it is important to know progress made a single patient over time.

\section{- Suggestion}

Based on time period zero (base period), 1, 2, so on, construct WBI enabling formation of chain indices like $W B I_{20}=W B I_{21} \times W B I_{10}$. This will help drawing path of improvement of WBI for a country from the base period. Countries may be compared in terms of such paths also.

\section{Non uniform selection of Indicators, Transformation and Aggregation}

Usefulness of WBI depends heavily on the underlying construction scheme (Organisation for Economic Co-operation and Development-OECD, 2008), with stages like selection of domains/indicators, scaling/normalization, selection of weights and aggregation method. Each stage influences the resultant WBI.

\section{Selection of indicators}

WBIs differ in concepts, purposes and selection of domains and associated indicators. Concepts like happiness, satisfaction, etc. have been understood and measured differently. Even for a same measure, dimensions and indicators got changed in subsequent versions. For example, eight goals of Millennium Development Goals have been replaced by 17 goals in Sustainable Development Goals (SDG) (Fukuda-Parr, 2016).

Sen (1985) suggested capability approach of multidimensional wellbeing. Yang (2018) opined that "functioning" carried out are used as a proxy of "capabilities" and proposed the preference index approach. However, the preference index approach uses ordinal and noncomparable information about individual preferences to construct a comparable WBI without aiming at a definitive wellbeing measure. Indicators may focus on the "feeling" component of wellbeing (say happiness) or on "thinking" component (say fulfillment) (Ryff \& Keyes, 1995). Almost every measure of WBI has been criticized for not inclusion of other domains or indicators. The Table 1 shows domains and indicators corresponding to an illustrative list of WBIs. 
TABLE 1.

Wellbeing Indices and number of indicators.

\begin{tabular}{|c|c|c|c|c|}
\hline $\begin{array}{l}\text { Sl. } \\
\text { No. }\end{array}$ & Index & $\begin{array}{l}\text { No. of } \\
\text { Indicators }\end{array}$ & Domains & Ignores \\
\hline 1 & $\begin{array}{l}\text { Australia Unity Wellbeing Index } \\
\text { (www.australianunity.com.au/ } \\
\text { aboutus/Wellbeing/AUWB) }\end{array}$ & 8 & $\begin{array}{l}8 \text { (Achievement, Health, Future } \\
\text { security, Safety, Community } \\
\text { vitality, Relationships, Standards of } \\
\text { living \& Spirituality). }\end{array}$ & $\begin{array}{l}\text { Basic access, Economy, } \\
\text { Education, Governance, Life } \\
\text { expectancy, Culture, Income, } \\
\text { Personal freedom, Use of time, work- } \\
\text { life balance, etc. }\end{array}$ \\
\hline 2 & Canadian index of Wellbeing & 64 & $\begin{array}{l}8 \text { (Community vitality, Culture, } \\
\text { Education, Health, Future Security, } \\
\text { Safety, Relationships \& Standards } \\
\text { of living). }\end{array}$ & $\begin{array}{l}\text { Subjective Well-being(SWB), Basic } \\
\text { access, Economy, Income, Safety, } \\
\text { Personal freedom, etc. }\end{array}$ \\
\hline 3 & $\begin{array}{l}\text { Gallup-Healthways Wellbeing Index } \\
\text { (www.wellbeingindex.com) }\end{array}$ & 40 & $\begin{array}{l}6 \text { (Basic access, Health, } \\
\text { Engagement, Emotional Health, } \\
\text { Life satisfaction \&Working life). }\end{array}$ & $\begin{array}{l}\text { Culture, Income, Jobs, Environment, } \\
\text { Life expectancy, Safety, Personal } \\
\text { freedom, etc. }\end{array}$ \\
\hline
\end{tabular}

$4 \quad$ Gross National Happiness Index (www.grossnationalhappiness.com)

5

Happy Planet Index

(www.happyplanetindex.org)

32

(modified

to include 72 indicators)

3

104

Legatum Prosperity Index (www.prosperity.com)

OECD Better Life Index (BLI)

(www.oecdbetterlifein dex.org)

National Accounts of Wellbeing

8 (NAWB)

www.nationalaccountsofwellbeing.org

Social Progress Index

9 (http://www.socialprogressimperative. org/data/spi)

UK National ONS Wellbeing Index 10 (www.ons.gov.UK/ons/guide-method/ user guidance/wellbeing/index.html)

11 Human Development Index (HDI) (www.hdr.undp.org)

Quality of life WHOQL 100 Healthrelated quality of life (HRQOL)

12 (www.qualityindicators. ahrq.gov/ Downloads/Modules/ PSI/ PSI_ Composite_Development.pdf)
10 (Community vitality, Health, Education, Culture, SWB including Spirituality, Economy, Environment, Political, Human needs met and Time use).

3 (Ecological footprint, Life expectancy \& Sustainable economics).

9 (Education, Economic Quality, Health, Business Environment, Safety \& Security, Governance, Personal Freedom, Social Capital \& Natural Environment).

11 (Civic engagement, Health, Community, Education, Environment Income; Jobs, Housing, Life satisfaction, Safety \&Work-life balance).

Personal wellbeing (5 Components) and Social well-being (2 components).

8 (Education, Health, Environment, Insecurity: economic and Physical, Political voice and governance, Material living standards, Personal activities including work, Social connections and relationships).

10 (Where we live, Natural environment, Economy, Education and skills, Governance, Health, Relationships, Personal finance, Personal wellbeing \& What we do).

4 (Education, Health, Life expectancy \& Standards of living). The 2012 HDI Report also contains the Gender Inequality Index (GII) for186 countries.

6 (Physical health, social relations, psychological health, environment, level of independence, and spirituality).

Physical and mental health symptoms, including functioning and perceptions of general health.
Basic access, Economy, Jobs, Income, Housing, Safety, Social capital, Worklife balance, etc.

Economic status, quality of life or income equality, distribution of wealth, government spending, human rights violation, literacy rate, Environmental issues, etc.

Basic access, Incomes, Jobs, Environment, Life expectancy, Life satisfaction, etc.

Basic access, Economy, Social capital, Environment related areas like air - water -noise pollutions, social networks that sustain relationships, and freedom of speech.

Safety, Education/skills, Environment, Life-expectancy, etc.

Basic access, Economy, Life expectancy, Life satisfaction, Personal freedom, Governance, Social capital, etc.

Culture, Environment, Future security, Income, Life expectancy, Safety, Social capital, etc.

Psychological \& Personal wellbeing and Experienced Wellbeing like equity, political freedoms, human rights, social cohesion, sustainability, happiness, engagement in community, etc.

Less useful to identify specific public health interventions. 
The Table 1 revels that popular indicator are Health, Environment and Education. Selected indicators are not comprehensive to reflect the dynamics of the psycho-social aspects of wellbeing. Reporting of HRQOL varies among persons suffering from different types of diseases (Centra, 1998). Increasing number of indicators for BLI was suggested (Kasparian \& Rolland, 2012). Allied concepts like quality of life, living standards, social welfare, fulfillment of needs, capability, life satisfaction, and happiness etc. are used without agreement in meaning and clarity of related objectives. Thus, a WBI may both measure and miss in multiple ways (Clark \& McGillivray, 2007).

Other issues are correlations between the indicators and between indicators with WBI. High correlation between two indicators results in multicolinearity, implying repeated measurement of same trait. Negative correlations indicate statistical incoherence for the WBI. HDI had poor correlations with mental wellbeing, empowerment, political freedom, social and community relations, political and economic stability, environment, etc. (Ranis, Stewart \& Samman, 2006). Poor correlation between economic growth and improvement in education, health do not justify exclusion of any of them. High correlation of one indicator with WBI may not require construction of WBI and instead the former could well be used. Relevance of indicators should not be judged on the basis of correlations alone.

\section{- Suggestion}

Selection of indicators and domains may be made for the purpose ensuring that the set of chosen indicators gives a fair summary of the whole with adequate specification of concept and equal applicability to each unit. Decide aggregation procedure to accommodate all relevant indicators irrespective of inter-correlations. Possible aggregation procedure could be geometric mean of $X_{\mathrm{C}}$ and $X_{0}$ as in equation 2 :

$$
\sqrt[n]{\frac{X_{1 c} \cdot X_{2 c} \ldots \ldots \ldots X_{n c}}{X_{10} \cdot X_{20} \ldots \ldots X_{n 0}}}
$$

Where current and base period vectors are respectively:

$$
\begin{aligned}
& x_{\mathrm{c}}=\left(x_{1 \mathrm{c}}, x_{2 c}, \ldots, x_{\mathrm{nc}}\right)^{\mathrm{T}} \\
& x_{0}=\left(x_{10}, x_{20}, \ldots, x_{\mathrm{n} 0}\right)^{\mathrm{T}} \\
& \text { Scaling/normalization of raw data }
\end{aligned}
$$

\section{Scaling/normalization of raw data}

The selected indicators in different units differ in score-ranges and distributions. Raw scores are often transformed (scaled or normalized/standardized). However, there are many such methods, each having effects on the WBI. Correlation between Life expectancy and HDI exceeded the same between Life expectancy and GDP but the inequality got reversed with logarithmic transformations (Kovacevic, 2011). Transformation changes shape of the original distribution, Basic idea is to have unit free values preferably in a desired range and following same distribution. Common methods of scaling and normalization of indicators are: 


\section{Min - Max Scaling}

Equation 3 transform raw score to [0, 1]. For negatively related indicator, formula is indicated equation 4. Example: HDI, BLI, PWI, etc. Such scaling indicates relative performance (not absolute performance) of a country and depends heavily on $X_{\text {Max }}$ and $X_{\text {Min }}$ which could be unreliable outliers. Performance of a third country can also influence relative ranking of two countries (Kasparian \& Rolland, 2012). Difference in variance is not fully eliminated (OECD, 2008). Decrease in performances of the worst performing country may increase $Z$ - value of $A$, even if $X$ for country-A remains unchanged. If $X_{\mathrm{Min}}$ is changed, ranking and relative valuations may be changed due to change in marginal rates of substitution (Seth \& Villar, 2017). Gain in $Z$ per unit increase in $X$ is not uniform at all values of $X$.

$$
\begin{aligned}
& Z=\frac{X-X_{M i n}}{X_{M a x}-X_{M i n}} \\
& Z=1-\frac{X-X_{M i n}}{X_{\text {Max }}-X_{M i n}}
\end{aligned}
$$

TABLE 2.

Hypothetical data with four indicators and six countries for effect of Min.- Max. transformation.

\begin{tabular}{llllllllr}
\hline \multicolumn{3}{c}{ t-th Year } \\
\hline Country & I - 1 & \multicolumn{1}{c}{ I - 2 (Negative) } & I - 3 & I - 4 & I - 1 & I - 2 (Negative) & I - 3 & I - 4 \\
\hline 1 & 104 & 22 & 32 & 76.3 & 105 & 23 & 33 & 77.3 \\
2 & 107 & 22.4 & 30 & 20 & 108 & 23.4 & 31 & 21 \\
3 & 114 & 30.3 & 32 & 25.7 & 115 & 31.3 & 33 & 26.7 \\
4 & 117 & 25 & 40 & 10.8 & 118 & 26 & 41 & 11.8 \\
5 & 120 & 26 & 28 & 17.3 & 121 & 27 & 29 & 18.3 \\
6 & 123 & 26.5 & 20 & 16.4 & 124 & 27.5 & 21 & 17.4 \\
\hline
\end{tabular}

( For $(t+1)$-th Year, each indicator was increased by 1 unit for each country.

Major observations are:

a. Normalized value of an indicator by Min - Max transformation, remained unchanged in the t-th year and $(t+1)$-th year.

b. Index score of countries remained unchanged in the $t$-th year and $(t+1)$-th year for Method 1 and 2, since Min-Max scaling is invariant under change of origin. The approaches failed to reflect improvement in the $(t+1)$-th year registered by each country on each indicator. Thus, Min-Max scaling and AM \& GM approaches of normalized indicators failed to show responsiveness of WBI.

c. As per the Method 2, Index score $=0$ for the worst performing country in an indicator. In this approach, number of countries with zero Index score is equal to the number of indicators, if minimum raw score on different indicators is achieved by different countries. The approach failed to distinguish countries with zero scores and rank such countries. 
d. However, Index scores for the $(t+1)$-th year were different for different countries as per Method 3 and Method 4. Each of the six countries got a unique rank.

e. Lowest Coefficient of Variation (CV) for Method 4 indicates lesser level of dispersion around the mean.

f. The proposed method of geometric aggregation of ratio of indicator scores at two different time periods is preferred.

\section{Normalization/Standardization}

Equation 5 follows $\mathrm{N}[0,1]$. $Z$-values can be converted to a desired range. Used by many indices including National Accounts of Wellbeing-NAWB and recommended for the WHO index of health system performance (Scientific Peer Review Group on Health Systems Performance Assessment \& World Health Organization-SPRG, 2001).

$$
Z=\frac{X-\operatorname{Mean}(X)}{S D(X)}
$$

TABLE 3.

Normalized values of indicators*.

\begin{tabular}{|c|c|c|c|c|c|c|c|c|c|c|}
\hline \multirow[b]{2}{*}{ Country } & \multicolumn{5}{|c|}{ t-th Year } & \multicolumn{5}{|c|}{$(t+1)$-th Year } \\
\hline & I - 1 & $\begin{array}{c}\mathrm{I}-2 \\
\text { (Negative) }\end{array}$ & $\begin{array}{c}\mathrm{I}- \\
3\end{array}$ & I - 4 & Total & I - 1 & $\begin{array}{c}\text { I - } 2 \\
\text { (Negative) }\end{array}$ & $\begin{array}{c}\mathrm{I}- \\
3\end{array}$ & I - 4 & Total \\
\hline 1 & 0 & 1 & 0.6 & 1 & 2.6 & 0 & 1 & 0.6 & 1 & 2.6 \\
\hline 2 & 0.15789 & 0.95181 & 0.5 & 0.14046 & 1.75016 & 0.15789 & 0.95181 & 0.5 & 0.14046 & 1.75016 \\
\hline 3 & 0.52632 & 0 & 0.6 & 0.22748 & 1.35377 & 0.52632 & 0 & 0.6 & 0.22748 & 1.35377 \\
\hline 4 & 0.68421 & 0.63855 & 1 & 0 & 2.32276 & 0.68421 & 0.63855 & 1 & 0 & 2.32276 \\
\hline 5 & 0.84210 & 0.51807 & 0.4 & 0.09924 & 1.85941 & 0.84210 & 0.51807 & 0.4 & 0.09924 & 1.85941 \\
\hline 6 & 1 & 0.45783 & 0 & 0.08550 & 1.54333 & & & & & \\
\hline
\end{tabular}

"Normalization by $\mathrm{Z}=\left(X-X_{\mathrm{Min}}\right) /\left(X_{\mathrm{Max}}-X_{\mathrm{Min}}\right)$ for each positive indicator and $=1-\left(X-X_{\mathrm{Min}}\right) /\left(X_{\mathrm{Max}}-X_{\mathrm{Min}}\right)$ for negative indicator.

Other transformations are:

$$
Z_{i}=\frac{X_{i}}{\bar{X}} \times 100
$$

- Equation 6 is less robust to the influence of outliers and is linearly related to Proportionate Normalization where $Z_{\mathrm{i}}=X_{\mathrm{i}} /\left(\sum X_{\mathrm{i}}\right)$.

$$
Z_{i}=\frac{X_{i}}{X_{\operatorname{Max}}} \times 100
$$

- Equation 7 depends on $X_{\text {Max }}$. Used in Summary Innovation Index (Saisana \& Tarantola, 2002). 


$$
Y_{i}^{t}=\frac{X_{i}^{t}-X_{i}^{t-1}}{X_{i}^{t}} \times 100
$$

- For longitudinal data, equation 8 where $t$ denotes time period (Example: European Commission, Saisana \& Tarantola, 2001) or ratio with $X_{\mathrm{i}}^{0}$, the base period as in equation 9 for each positive indicator/domain and equation 10 where $j$ denotes a negative indicator/ domain.

$$
\begin{aligned}
& \frac{X_{i}^{t}}{X_{i}^{0}} \times 100 \\
& \frac{X_{j}^{0}}{X_{j}^{t}} \times 100
\end{aligned}
$$

Assuming equal importance, CIW takes average of such percentages with $n$-indicators as in equation 11 where $i$ and $j$ denotes respectively positively related and negatively related indicator/domain and $n_{1}+n_{2}=n$. However, CIW is not monotonic. For example, consider the case with one positive indicator $(X+)$ and one negative indicator $\left(X^{-}\right)$. Let $\left(X^{+}\right)$takes values 104 and 120 and values of $\left(X^{-}\right)$are 22 and 28 respectively for $t_{1}$ and $t_{2}$. Here, $C I W_{\mathrm{t} 1}=C I W_{\mathrm{t} 2}$. Moreover, equal importance to the indicators and average of percentages and reciprocal of percentages are not justified.

$$
\frac{1}{n}\left[\left(\sum_{i=1}^{n_{1}} \frac{X_{i}^{t}}{X_{i}^{0}} \times 100\right)+\left(\sum_{j=1}^{n_{2}} \frac{X_{j}^{0}}{X_{j}^{t}} \times 100\right)\right]
$$

- Logarithmic transformation of an indicator: $Y_{\mathrm{i}}=\ln \left(X_{\mathrm{i}}\right)$.

$$
\text { Income }_{X}=\frac{\log _{e}{ }^{X}-\log _{e}\left(X_{\text {Min }}\right)}{\log _{e}\left(X_{\text {Max }}\right)-\log _{e}\left(_{\text {Min }}\right)}
$$

For the Income component, HDI (Kovacevic, 2011) used equation 12.

Here, rate of increase of Income $_{\mathrm{X}}$ is different for different values of $X$. Moreover, Income $\mathrm{X}$ is not invariant under change of origin. Consider the example with hypothetical data in Table 4:

TABLE 4.

Increment of due to increase in $X$ and Effect of change of origin.

\begin{tabular}{ccccccc}
\hline \multirow{2}{*}{$X$} & $X_{\text {Min }}$ & $X_{\text {Max }}$ & Income & Increment & \multicolumn{2}{c}{ Effect of change of origin (Add 7 to $X, X_{\text {Min }} \& X_{\text {Max }}$ ) } \\
\cline { 6 - 7 } & & & & Modified $X$ & \multicolumn{1}{c}{ Income $e_{\mathrm{X}}$} \\
\hline 101 & 100 & 175 & 0.017781 & & 108 & 0.017513 \\
102 & 100 & 175 & 0.035386 & 0.035039 (102 from 101) & 109 & 0.034864 \\
169 & 100 & 175 & 0.937659 & & 176 & 0.93689 \\
170 & 100 & 175 & 0.948201 & 0.010542 (170 from 169) & 177 & 0.947555 \\
\hline
\end{tabular}

Source: Author. 
The transformation fails to satisfy Translation Invariance property and consistency in aggregation which are considered as desired (Chakravarty, 2003). Changing $X_{\min }$ to $50 \Longrightarrow$ Income $_{140}>$ Income $_{85}+$ Income $_{45}$. Thus, the index depends on the normalization methods applied to different indicators.

\section{- Suggestion}

Find WBI of a country considering performance of that country only. Normalizing or scaling of indicators may be avoided if WBI is defined as Cosine similarities between the current and base period vector $X_{\mathrm{c}}$ and $X_{0}$ respectively or GM of the ratios $X_{\mathrm{ic}} / X_{\mathrm{i} 0}$, where:

$X_{\mathrm{c}}=\left(X_{1 \mathrm{c}}, X_{2 \mathrm{c}}, \ldots, X_{\mathrm{nc}}\right)^{\mathrm{T}}$

$X_{0}=\left(X_{10}, X_{20}, \ldots, X_{\text {no }}\right)^{\mathrm{T}}$

\section{Combining the indicators}

Method of combining the indicators is to find the function $f$ from $R^{\mathrm{n}} \rightarrow R$. Such function can affect the properties of the WBI and may have major implications on the final index. Addition/Arithmetic Mean (AM) assumes at least in interval level measurement and equal importance to the indicators. This may not be meaningful since a low level of positive emotions can be countered by a high level of income. Measures like Quality of Life, CWI, PWI, etc. give equal weights and aggregates the indicators within each domain by AM. Domains get equal weights in Gross National Happiness (GNH) but different weights to the indicators. Equal weights are criticized for compensatory approach, no differentiation of essential and less important indicators and involve subjective judgment (Ray, 2008; Mikulić, Kožić \& Krešić, 2015).

WBI by weighted sum considers (equation 13):

$$
\mathrm{WBI}=\sum_{i=1}^{n} W_{i} X_{i}
$$

Where $0<W_{\mathrm{i}}<1$ and $\Sigma W_{\mathrm{i}}=1$.

$$
\sum_{i=1}^{n} W_{i}
$$

The convex property is violated if equation $14 \neq 1$. Methods of choosing weights differ significantly. Experts are involved in Budget Allocation Process; Analytic Hierarchy Process (used in SWB, Urban quality of Life) to assign importance of each criterion relative to the others. Results are ordinal and weights are subjective. Raters' reliability is an additional issue. Human Wellbeing Index (HWI), Ecosystem Well Being Index (EWI) used weighted average as equation 15. Chosen weights serve as 'trade-offs' and also 'importance coefficients' in such aggregation process. The ratio $W_{1} / W_{2}$ indicates the amount of indicator-2 to be sacrificed to gain an extra unit of indicator -1 . Such trade- offs may not be meaningful 
when the indicators relate to monetary growth and improvement in non-monetary areas like health, education, feeling happy, etc.

$$
\frac{1}{n} \sum_{i=1}^{n} W_{i} X_{i}
$$

Weights from PCA (factor loadings of the first component) tend to ignore indictors having weak correlations with WBI, even if they are theoretically and practically important. Such weights are not invariant under change of scale and vary over time and space. SPI transforms component scores to 0 (best case) to100 (worst case) and finds PCA weights to the indicators of each domain. It ignores judgments as to what are important.

Data Envelopment Analysis - Benefit-of-the-Doubt — approach was used in wellbeing and quality of life composite indicators (Mizobuchi, 2014). It maximizes relative efficiency score for each Decision Making Unit (DMU) following Linear Programming (LP) approach. Here, weights are obtained satisfying the constraints of the LP and deriving a single aggregate measure for each DMU. The approach depends on the chosen normalization method. Instead of a unique weight to an indicator, a collection of weights are computed for each observation and thus complicates the interpretation of the results.

Distance $P_{2}$ to measure social welfare (Zarzosa \& Somarriba, 2012) considers a reference vector $X_{0}$ by the minimum values of each partial indicator and Frechet distance for the $i$-th observation. The method depends on order of the indicators. Not suitable when the correlations between the indicators are weak and linearity is not justified. Pinar (2019) suggested generalized weighted mean of order $\beta$ to find WBI of the $i$-th country at time $t$ as equation 16 :

$$
W B I_{i}^{t}=\left[\sum_{j=1}^{n} W_{j} \times\left(Z_{i j}^{t}\right)^{\beta}\right]^{\frac{1}{\beta}}
$$

Where (equation 17):

$$
Z_{i j}^{t}=\frac{X_{i j}^{t}-\operatorname{Min}\left(X_{j}\right)}{\operatorname{Max}\left(X_{j}\right)-\operatorname{Min}\left(X_{j}\right)}
$$

$W_{\mathrm{j}}$ denotes weight of the $\mathrm{j}$-th indicator and $\beta$ is a parameter. This becomes GM if $\beta=0$ and AM for $\beta=1$.

Chakrabartty (2017) proposed to find weight vector $W=\left(W_{1}, W_{2}, \ldots, W_{\mathrm{n}}\right)^{\mathrm{T}}$ such that equation $14=1$ and variance of equation 13 is minimum. Instead of $X i$ 's, if standardized scores (equation 18; equation 19):

$$
\begin{aligned}
& Z_{i j}=\frac{X_{i j}-\overline{X_{j}}}{S_{X_{j}}} \\
& r_{Y, Z_{i}}=r_{Y, Z_{j}}=\frac{1}{\sqrt{e^{T} R^{-1} e}}
\end{aligned}
$$


Where (equation 20):

$$
Y=\sum_{i=1}^{n} W_{i} X_{i}
$$

$R$ is the correlation matrix and $i \neq j$.

\section{- Suggestion}

Since, no weighting system can be above criticism (Greco, Ishizaka, Tasiou \& Torrisi, 2019), attempts could be made to develop WBI avoiding weights to the indicators/domains. One possible approach is to define WBI as GM of the ratios $X_{\mathrm{ic}} / X_{\mathrm{i} 0}$ for $i=1,2, \ldots, n$.

\section{Aggregation, other than weighted sum}

Through an axiomatic approach, Chakravarty (2003) suggested aggregation by AM of the normalized values obtained by Min-Max function. HDI has shifted from AM to GM of normalized indices since 2010, avoiding perfect substitutability. However, for the worst performing country in an indicator, $Z=0$ and GM of that country will be zero. Similarly, the best performing country for an indicator will have $Z=1$ and GM of that country will remain unchanged under exclusion or inclusion of that indicator.

To reduce skew of the data, National Accounts of Wellbeing-NAWB used the aggregation formula (21):

$$
\frac{5 Z_{i}}{m_{i}\left(X_{i}\right)+C_{i}}+5
$$

Where (equation 22; equation 23; equation 24):

$$
\begin{aligned}
& m_{i}=\frac{\operatorname{Min}_{i}+\operatorname{Max}_{i}}{\operatorname{Min}_{i}-\operatorname{Max}_{i}} \\
& C_{i}=\frac{2 \operatorname{Min}_{i} \operatorname{Max}_{i}}{\operatorname{Min}_{i}-\operatorname{Max}_{i}} \\
& Z_{i}=\frac{X_{i}-X_{\text {Min }}}{X_{\text {Max }}-X_{\text {Min }}}
\end{aligned}
$$

Where $0 \leq X_{\mathrm{i}} \leq 10$.

GNH with 249 questions and 750 variables is calculated as $G N H=1-H_{\mathrm{n}} A_{\mathrm{n}}$ where $H_{\mathrm{n}}$ denotespercentage of people who have not achieved sufficiency in six domains (Not-yethappy) and $A_{\mathrm{n}}$ is the average of proportion of domains in which "Not-yet-happy" people lack sufficiency (Kelley, 2012). GNH depends heavily on threshold values, reduction of which increases percentage of respondents as happy in life satisfaction. 
Mazziotta and Pareto (2007) Index (MPI) for the i-th country as in equation 25:

$$
M P I_{i}^{+/-}=M_{Z_{i}}\left(1 \pm C V_{i}^{2}\right)
$$

Where (equation 26; equation 27; equation 28; equation 29):

$$
\begin{aligned}
& C V_{i}=\frac{M_{Z_{i}}}{S_{Z_{i}}} \\
& M_{Z_{i}}=\frac{\sum_{j=1}^{m} Z_{i j}}{m} \\
& S_{Z_{i}}=\sqrt{\frac{\sum_{j=1}^{m}\left(Z_{i j}-M_{Z_{i}}\right)^{2}}{m}} \\
& Z_{i j}=100 \pm\left(\frac{X_{i j}-M_{X_{j}}}{S_{X_{j}}}\right) \cdot 10
\end{aligned}
$$

The sign is + if the indicator is positively related and - otherwise (Mazziotta \& Pareto, 2007). MPI favours high-performing unit and issue of compensability in aggregation have been questioned (Greco et al., 2019).

Herrero, Martinez and Villar (2010) followed axiomatic approach and suggested GM of the mean values of each characteristic. WBI for a group of countries uses average of WBIs over a set of countries. Alternatively, average values of the indicators observed in the set of all countries are used in computing Group WBI, assuming such average values are additive. Lack of joint distribution of wellbeing in various dimensions and data on the indicators are not obtained from the same set of sampling units within a country - are important issues in this context.

\section{- Suggestion}

WBI by cosine similarity or GM can accommodate all relevant indicators, facilitates computation of the index for a country and a group of countries.

\section{Methodology}

Assuming completion of selection of domains and associated indicators, following preprocessing of data are proposed for construction of WBI avoiding scaling of raw data and choosing weights:

\section{Data pre-processing}

Pre-processing of data in the following three stages are proposed:

Step 1: Convert each indicator to be positively related to WBI. Take reciprocal of each negative indicator whose lower value tends to increase value of WBI. 
Step 2: Convert raw scores from Likert items with equal number of response categories, to continuous, monotonic, equidistant scores with same item-total correlation as suggested by Chakrabartty (2019):

a. Assign 1, 2, 3, 4, 5, etc. to the levels or response categories to Likert items avoiding zero to facilitate meaningful application of mathematical operations.

b. Convert raw Likert scores to equidistant scores by data driven weights to response categories of different items so that $W_{1}, 2 W_{2}, 3 W_{3}, 4 W_{4}, 5 W_{5}$ forms as Arithmetic Progression and generate continuous scores satisfying monotonic condition, equidistant property (to facilitate addition) with zero ties (to distinguish the respondents with same raw score).

c. Standardized equidistant scores $(X)$ of each item as in the equation 30 where $Z \sim N[0,1]$.

d. Take further weights to items to make the test score equi-correlated with the items and thus better justify addition of such converted item scores.

$$
Z=\frac{X-\bar{X}}{S D(X)}
$$

Step 3: For Likert scale consisting of different response categories, consider several subtests, each containing $K$-point items for $K=3,4,5,6$. Follow above mentioned steps a), b) and c) for each subtest. Transform the scores obtained at d) to have proposed mean and proposed SD and add them to get subtest scores and test scores. Subtest scores obtained in this fashion will be normally distributed with same mean and variance for all the $K$-point scales.

\section{Proposed methods}

Let $X_{\mathrm{m} \times \mathrm{n}}$ be the matrix for m-countries and n-indicators where each row vector $X_{\mathrm{c}}=\left(X_{1 \mathrm{c}}, X_{2 \mathrm{c}}, \ldots, X_{\mathrm{nc}}\right)^{\mathrm{T}}$ represents performance of a country on $n$-indicators in the current period. Here, $X_{\text {ic }}>0 \forall i=1,2, \ldots, n$ have been obtained after the data pre-processing presented above. Let corresponding base period vector be $X_{0}=\left(X_{10}, X_{20}, \ldots \ldots, X_{\mathrm{n} 0}\right)^{\mathrm{T}}$. Let $\theta$ be the angle between $X_{\mathrm{c}}$ and $X_{0}$.

Cosine similarity approach:

$$
W B I_{c 0}=\operatorname{Cos} \theta=\frac{X_{c}{ }^{T} X_{0}}{\left\|X_{c}\right\|\left\|X_{0}\right\|}
$$

Where $\left\|X_{\mathrm{c}}\right\|$ and $\left\|X_{0}\right\|$ are length of and respectively and $0 \leq \operatorname{Cos} \theta \leq 1$.

The equation 31 indicates overall achievements (as reflected by $X_{c}$ ) made by a country over the baseperiod (as reflected by $X_{0}$ ). Example: Disability Index (Chakrabartty, 2019b). Lower $\theta$ implies higher $\operatorname{Cos} \theta$. Lower values of $\operatorname{Cos} \theta$ make the data more homogeneous. Association between $i$-th and $j$-th country is evaluated by by the equation 32 for $i \neq j$.

$$
\operatorname{Cos} \theta_{i j}=\frac{X_{i}^{T} X_{j}}{\left\|X_{i}\right\|\left\|X_{j}\right\|}
$$


TABLE 5.

Proposed method in terms of $\operatorname{Cos} \theta=X_{\mathrm{t}}^{\mathrm{T}} X_{\mathrm{t}+1} /\left\|X_{(\mathrm{t}+1)}\right\| X_{\mathrm{t}} \|$.

\begin{tabular}{llrrr}
\hline Country & $X_{\mathrm{t}}^{\mathrm{T}} X_{\mathrm{t}+1}$ & \multicolumn{2}{c}{ Length } & $\operatorname{Cos} \theta$ \\
\hline 1 & & $\left\|X_{\mathrm{t}}\right\|$ & $\left\|X_{\mathrm{t}+1}\right\|$ & \\
\hline 2 & 17873.99 & 132.8973 & 134.4964 & 0.999988 \\
3 & 12906 & 112.9115 & 114.3066 & 0.999959 \\
4 & 14852.19 & 121.1631 & 122.5842 & 0.999967 \\
5 & 15573.44 & 124.1195 & 125.4761 & 0.999963 \\
6 & 15648.59 & 124.4319 & 125.7652 & 0.999961 \\
\hline
\end{tabular}

Note: To compute $X_{\mathrm{t}}^{\mathrm{T}} X_{(\mathrm{t}+1)}$ of a country, reciprocal of the negative indicator was considered.

\section{- Mean and variance of $\operatorname{Cos} \theta$}

Triangle inequality is not satisfied by $\operatorname{Cos} \theta_{\mathrm{i}}$. Mean and $\mathrm{SD}$ of $\operatorname{Cos} \theta_{\mathrm{i}}$ for a group of countries may be obtained by the method suggested by Rao (1973) involving angles $\varnothing_{1}, \varnothing_{2}, \ldots, \varnothing_{\mathrm{k}}$, each obtained for vectors of unit length.

Mean or most preferred direction is estimated by the equation 33 and the dispersion by equation 34 .

$$
\begin{aligned}
& \bar{\emptyset}=\operatorname{Cot}^{-1} \frac{\sum_{i=1}^{k} \cos \emptyset_{i}}{\sum_{i=1}^{k} \sin \emptyset_{i}} \\
& \sqrt{1-r^{2}} \\
& \text { Where: } r^{2}=\left(\frac{\sum \cos \emptyset_{i}}{k}\right)^{2}+\left(\frac{\sum \sin \emptyset_{i}}{k}\right)^{2}
\end{aligned}
$$

Convert $X_{\mathrm{c}}$ and $X_{0}$ to $\Pi_{\mathrm{c}}$ and $\Pi_{0}$ where equation 35 and equation 36 , so that $\left\|\Pi_{\mathrm{c}}\right\|^{2}=\left\|\Pi_{0}\right\|^{2}=1$ :

$$
\begin{aligned}
& \pi_{i c}=\sqrt{\frac{X_{i c}}{\left\|X_{c}\right\|}} \\
& \pi_{i 0}=\sqrt{\frac{X_{i 0}}{\left\|X_{0}\right\|}}
\end{aligned}
$$

Thus, sample mean and sample dispersion of $\operatorname{Cos} \theta_{\mathrm{i}}$ can be computed respectively by equation 37 and equation 38 :

$$
\begin{aligned}
& \operatorname{Cos}(\bar{\theta})=\operatorname{Cos}\left(\operatorname{Cot}^{-1} \frac{\sum \operatorname{Cos} \theta_{i}}{\sum \operatorname{Sin} \theta_{i}}\right) \\
& \sqrt{1-\left[\left(\frac{\sum \operatorname{Cos} \emptyset_{i}}{k}\right)^{2}+\left(\frac{\sum \operatorname{Sin} \emptyset_{i}}{k}\right)^{2}\right]}
\end{aligned}
$$




\section{- Geometric Mean approach}

Deviating slightly from the geometric aggregation used in HDI (Kovacevic, 2011), proposed WBI for the current period could be Geometric mean of the ratios $X_{\mathrm{ic}} / X_{\mathrm{i} 0}$ for $i=1,2$, $\ldots, n$ as in equation 39:

$$
W B I_{c 0}=\sqrt[n]{\frac{C_{1 c} \cdot X_{2 c} \ldots \ldots \ldots X_{n c}}{X_{10} \cdot X_{20} \ldots \ldots . . X_{n 0}}}
$$

Avoiding the $n$-th root (equation 40 ):

$$
W B I_{c 0}=\frac{C_{1 c} \cdot X_{2 c} \ldots X_{n c}}{X_{10} \cdot X_{20} \ldots X_{n 0}}
$$

$\mathrm{WBI}_{\mathrm{c} 0}>1 \Rightarrow$ Overall improvement of a country from the base year.

TABLE 6 .

Proposed method of product of ratios of ( $t+1)$-th Year and $t$-th Year $\$$.

\begin{tabular}{lllllllc}
\hline Country & \multicolumn{1}{c}{ I - 1} & $\begin{array}{c}\text { I - } 2 \\
\text { (Negative) }\end{array}$ & \multicolumn{1}{c}{ I - 3 } & \multicolumn{1}{c}{ I - 4 } & $\begin{array}{c}\text { Product of } \\
\text { ratios }\end{array}$ & $\begin{array}{c}\text { GM=4th root of } \\
\text { Product of ratios }\end{array}$ & GM \\
\hline 1 & 1.009615 & 0.956522 & 1.03125 & 1.013106 & 1.00895 & 1.00223 & 100.223 \\
2 & 1.009346 & 0.957265 & 1.033333 & 1.05 & 1.04834 & 1.01187 & 101.1872 \\
3 & 1.008772 & 0.968051 & 1.03125 & 1.038911 & 1.04624 & 1.011366 & 101.1366 \\
4 & 1.008547 & 0.961538 & 1.025 & 1.092593 & 1.08604 & 1.020848 & 102.0848 \\
5 & 1.008333 & 0.962963 & 1.035714 & 1.057803 & 1.06380 & 1.015581 & 101.5581 \\
6 & 1.00813 & 0.963636 & 1.05 & 1.060976 & 1.08224 & 1.019955 & 101.9955 \\
\hline
\end{tabular}

$\$$ : For negative indicator, ratio of $t$-th year and $(t+1)$-th year was considered.

Progress of the $i$-th country in period $t$ over $(t-1)$-th period could be quantified by $W B I_{\text {it }}-$ $W B I_{(t-1)}$ or by equation 41 .

$$
\frac{W B I_{i}}{W B i_{(t-1)}}
$$

Progress and decline of the $i$-th indicator at $c$-th time period over the base period are reflected respectively by equation 42 or equation 43 .

$$
\begin{aligned}
& \frac{X_{i c}}{X_{i 0}}>1 \\
& \frac{X_{i c}}{X_{i 0}}<1
\end{aligned}
$$

From equation 40 (equation 44): 


$$
\begin{aligned}
\log W B I_{c 0} & =\sum_{i=1}^{n} \log X_{i c}-\sum_{i=1}^{n} \log X_{i 0} \\
& =\log \left[\frac{\left\|X_{c}\right\|}{\left\|X_{0}\right\|}\right]
\end{aligned}
$$

Since (equation 45):

$$
\begin{aligned}
\left\|X_{c}\right\| & =\sqrt{\sum_{i=1}^{n} X_{i c}^{2}} \Rightarrow \log \left\|X_{c}\right\| \\
& =\frac{1}{2}\left[2 \log X_{1 c}+2 \log X_{2 c}\right. \\
& \left.+\cdots \ldots+2 \log X_{n c}\right]=\sum_{i=1}^{n} \log X_{i c}
\end{aligned}
$$

Taking antilog, we get (equation 46):

$$
W B I_{c 0}=\frac{\left\|X_{c}\right\|}{\left\|X_{0}\right\|}
$$

Now, (equation 47):

$$
\begin{aligned}
\operatorname{Cos} \theta & =\frac{\sum_{i=1}^{n} X_{i c} X_{i 0}}{\left\|X_{c}\right\|\left\|X_{0}\right\|} \Rightarrow \frac{\operatorname{Cos} \theta}{W B I_{c 0}} \\
& =\frac{\sum_{i=1}^{n} X_{i c} X_{i 0}}{\left\|X_{c}\right\|^{2}} \Rightarrow \operatorname{Cos} \theta \\
& =\left(\frac{X_{c}^{T} X_{0}}{X_{c}^{T} X}\right) \cdot W B I_{c 0}
\end{aligned}
$$

Thus, $W B I_{\text {c0 }}$ by equation 40 and equation 31 are linearly related and slope of the relationship vary with data.

$W B I_{\mathrm{c} 0}$ may be multiplied by 100 to denote percentage changes from the base period.

Note that equation 31 and equation 40 are simple, avoid scaling/normalization and selection of weights, consider all selected indicators, even if they are in percentages or skewed.

TABLE 7.

Index values of countries by different methods of aggregation.

\begin{tabular}{lllll}
\hline Country & $\begin{array}{c}\text { AM of Normalized } \\
\text { Scores of Indicators }\end{array}$ & $\begin{array}{l}\text { GM of Normalized } \\
\text { Scores of indicators }\end{array}$ & $\begin{array}{l}\text { 4-th root of product of ratios of }(t+1) \text {-th } \\
\text { Year and t-th Year } \times 100(\text { Method 1.2) }\end{array}$ & $\begin{array}{c}\text { Cos } \theta \times 100 \\
(\text { Method 1.1) }\end{array}$ \\
\hline & $\begin{array}{l}t \text {-th Year } \\
\text { (unchanged in } \\
(t+1) \text {-th Year) }\end{array}$ & $\begin{array}{l}t \text {-th Year } \\
\text { (Unchanged in } \\
(t+1) \text {-th Year) }\end{array}$ & $\begin{array}{l}(t+1) \text {-th Year } \\
(t+1) \text {-th Year }\end{array}$ \\
1 & 0.65 & 0 & 100.223 & 99.9988 \\
2 & 0.43754 & 0.320522 & 101.1872 & 99.9959 \\
3 & 0.338449 & 0 & 101.1366 & 99.9967 \\
4 & 0.580691 & 0 & 102.0848 & 99.9963 \\
5 & 0.464854 & 0.362762 & 101.5581 & 99.9961 \\
6 & 0.38583 & 0 & 101.9955 & 99.9957 \\
\hline
\end{tabular}

Source: Author. 


\section{- Mean and variance of WBI as Geometric Mean}

Mean and variance of WBI for a group of countries may be found by considering distribution of GM which approaches the lognormal form (Alf \& Grossberg, 1979).

Let $\ln (W B I)=X$, where $\mathrm{X} \sim N\left(\mu_{\mathrm{x}}, \sigma_{\mathrm{x}}\right)$. Group mean of WBI (equation 48) and variance (equation 49).

$$
\begin{aligned}
& \mathrm{WBI}=e^{\mu_{X}+\frac{\sigma_{X}^{2}}{2}} \\
& \mathrm{WBI}=e^{2 \mu_{X}+\sigma_{X}{ }^{2}}\left(e^{\sigma_{X}{ }^{2}}-1\right)
\end{aligned}
$$

TABLE 8.

\begin{tabular}{|c|c|c|c|}
\hline & AM of Normalized Scores of Indicators & 4-th root of product of ratios $\times 100$ & $(\operatorname{Cos} \theta) \times 100$ \\
\hline Mean & 0.476227 & 101.3642 & 99.99657 \\
\hline $\begin{array}{l}\text { Standard } \\
\text { Deviation(SD) }\end{array}$ & 1.064877 & 0.624616 & 0.00103 \\
\hline $\begin{array}{l}\text { Coefficient of } \\
\text { Variation(CV) }\end{array}$ & 2.236068 & 0.006162 & 0.0000028 \\
\hline
\end{tabular}

Mean, $S D$ and Coefficient of variation of Index values at (t+1)-th Year

Source: Author.

\section{- Features of proposed methods}

Each of equations 40 and 31 satisfies the following desired properties:

- Depicts overall improvement/decline of a country in the current year from the base year by a continuous variable.

- WBI is monotonic since increase in an indicator $\left(X_{\mathrm{j}}\right) \Rightarrow$ increase in WBI.

- Gain in $W B I) /$ Gain in $X_{\mathrm{i}}$ is constant, i.e., $\mathrm{X}$ - WBI curve is linear.

- Independent of change of scale.

- Identifies critical areas showing decline in performances and requiring attention of the policymakers.

- $W B I_{\mathrm{c} 0}$ can be used for ranking and classifying the countries and even individuals with morbidity.

- If the base period data is replaced by the targets (say, SDG goals), $W B I_{\mathrm{c}, \mathrm{SDG}}$ will indicate how far a country is from the SDG goals at the $C$-th period.

- Possible to compute mean and variance of WBI for a group of countries.

- Reduces level of substitutability among component indicators, not affected much by outliers and produces no bias for developed or under-developed countries.

- Possible to have sub-indices for each domain by focusing on indicators related to that domain without further weights for domains. 
- Can be computed for properly defined sub-groups say religious groups, economically backward groups, elderly people with specific morbidity, etc.

Note that for the equation 40 :

$$
\frac{X_{i t}}{X_{i(t-1)}}<1
$$

- Critical areas are those for which equation 43 or equation 50.

- Time-reversal test is satisfied since $W B I_{\mathrm{t} 0} \cdot W B I_{\mathrm{ot}}=1$.

- Possible to form chain indices since $W B I_{20}=W B I_{21} \cdot W B I_{10}$ and to draw WBI graph of a country to reflect path of improvement/decline since the base period. The path may help interregional comparison of countries over time with respect to the WBI.

Thus, the proposed WBI in terms of the equation 40 with higher desirable properties is an improvement over the existent wellbeing measures.

\section{RESULTS}

Behavior of WBI by various approaches were illustrated using hypothetical data involving four indicators (including one negatively related to overall index) and six countries for $t$-the year and $(t+1)$-th year. For $(t+1)$-th year, each indicator was increased by 1 unit for each country. Normalized value of an indicator was obtained using the equation 3 for each positive indicator and the equation 4 for the negative indicator. Approaches considered are:

Method 1: Arithmetic mean (AM) of the normalized values of the indicators.

Method 2: GM of the normalized values of the indicators.

Method 3: Proposed method of WBI as GM of the ratios $X_{\mathrm{ic}} / X_{\mathrm{i} 0}$.

Method 4: Proposed method of WBI as cosine similarity between $X_{\mathrm{c}}$ and $X_{0}$.

For Method 3 and Method 4, reciprocal of raw scores were considered for the negatively related indicator.

\section{Discussions}

The paper reviews problems of construction of wellbeing at various stages and proposes two methods of measuring wellbeing without resorting to scaling or finding weights or reduction of dimensionality. The proposed wellbeing indices, in terms of Cosine similarity and Geometric Mean (GM) consider all chosen indicators and depict overall progress made by a country from base period or on Year-to-Year basis. The second one is a slight deviation from the HDI (Kovacevic, 2010). Instead of taking GM of the normalized values of the indicators, here GM is taken of the ratios $X_{\mathrm{ic}} / X_{\mathrm{i} 0}$ and thus, avoids normalization of the individual indicators. Linear relationship between the two proposed methods derived. Each proposed measure reduces level of substitutability among component indicators, not affected much by outliers, produces no bias for developed or underdeveloped countries and facilitates computation of man and SD for a group of countries. 
The GM approach facilitates formation of sub-indices for each domain by focusing on indicators related to that domain without further weights for domains.

Empirical verification highlights limitations of scaling and aggregation by AM or GM of the normalized values of indicators. The exercise shows higher responsiveness and discriminating power of the proposed methods.

However, the proposed methods have following limitations:

1. Introduction of new indicator requires estimation of value of that indicator in the base year and subsequent years.

2. Assumes no missing data.

3. Comparison of countries with respect to absolute values of WBI may not be meaningful since the base period figures vary across countries. However, countries may be meaningfully compared in terms of progress made from base period or on Year-to-Year basis.

4. Assumes positive value for each indicator for all periods.

5. Did not consider pattern of correlations between indicators. Effect of deleting highly or poorly correlated indicators on stability of WBI may be taken as a future study.

\section{Conclusions}

Between the two proposed measures, the GM approach is preferred for its additional features like linearity between gain in an indicator and gain in WBI, time-reversal test, easy identification of critical areas requiring attention and contribution of the indicators to WBI. The index can be further used for classification of countries, sub-groups and even individuals with morbidity in terms of overall wellbeing values. If the base period data is replaced by the targets (say, $\mathrm{SDG}$ goals), $W B I_{\mathrm{C}, \mathrm{SDG}}$ will indicate how far a country is from the SDG goals at the $C$-th time period. Simulation studies to find distribution of WBI in terms of $\operatorname{Cos} \theta$ and GM of ratios are suggested for future study.

\section{REFERENCES}

Alf, E. F. \& Grossberg, J. M. (1979). The geometric mean: Confidence limits and significance tests. Perception \&Psychophysics, 26(5), 419-421. https://doi.org/10.3758/BF03204171

Bastien, C. H., Vallieres, A. \& Morin, C. M. (2001). Validation of the Insomnia Severity. Index as an outcome measure for insomnia research. Sleep Medicine, 2(4), 297-307. https://doi.org/10.1016/s1389-9457(00)00065-4

Bailey, D. (2016). Democracy: the missing link in the devolution debate. New Economics Foundation Report. http://dx.doi.org/10.13140/RG.2.1.1892.2483

Becker, W., Saisana, M., Paruolo, P. \& Vandecasteele, I. (2017). Weights and importance in composite indicators: Closing the gap. Ecological Indicators, 80, 12-22. https://doi. org/10.1016/j.ecolind.2017.03.056

Centra, L. (1998). New information about health-related quality of life. NACCHO News, $13(2)$. 
Chakrabartty, S. N. (2020). Combining Likert items with different number of Response categories. Proceedings on Engineering Sciences, 2(3), 311-322. http://dx.doi.org/10.24874/ PES02.03.010

Chakrabartty, S. N. (2019). Limitations of Insomnia Severity Index and possible remedies. JSM Neurological Disorders and Stroke, 5, 1-9. Available from https://www.jsmcentral. org/NeurologicalDisorders/jsmnds284798.pdf

Chakrabartty, S. N. (2019b). Alternate measure of disability intensity: Modified Rankin Scale. Journal of Stroke Medicine, 2(2), 111-118, https://doi.org/10.1177/2516608519870703

Chakrabartty, S. N. (2017). Composite Index: Methods and Properties. Journal of Applied Quantitative Methods, 12(2), 31-41. Available: https://www.jaqm.ro/issues/volume12,issue-2/2_SA.PHP

Chakravarty, S. R. (2003). A Generalized Human Development Index. Review of Development Economics, 7(1), 99-114. https://doi.org/10.1111/1467-9361.00178

Clark, D. \& Mark McGillivray, M. (2007). Measuring Human Well-being: Key Findings and Policy Lessons. Policy Brief 3, 1-8. Available: https:/www.wider.unu.edu/sites/default/ files/PB2007-003.pdf

Cooke,P.J.,Melchert,T.P.\&Connor, K.(2016).Measuringwell-being:Areview ofinstruments. The Counseling Psychologist, 44(5), 730-757. https://doi.org/10.1177\%2F0011000016633507

Cummins, R., Eckersley, R., Pallant, J., Van Vugt, J. \& Misajon, R. (2003). Developing a national index of subjective wellbeing: The Australian unity Wellbeing Index. Social Indicators Research, 64(2), 159-190. https://doi.org/10.1023/A:1024704320683

Finn, R. H. (1972). Effects of some variations in rating scale characteristics on the means and reliabilities of ratings. Educational and Psychological Measurement, 32(2), 255-265. https://doi.org/10.1177\%2F001316447203200203

Fukuda-Parr, S. (2016). From the Millennium Development Goals to the Sustainable Development Goals: shifts in purpose, concept, and politics of global goal setting for development. Gender \& Development, 24(1), 43-52. https://doi.org/10.1080/13552074.2016.1145 895

Greco, S., Ishizaka, A., Tasiou, M. \& Torrisi, G. (2019). On the Methodological Framework of Composite Indices: A Review of the Issues of Weighting, Aggregation, and Robustness. Social Indicators Research, 141(3), 61-94. https://doi.org/10.1007/s11205-017-1832-9

Herrero, C., Martinez, R. \& Villar, A. (2010). Multidimensional social evaluation. An application to the measurement of human development. Review of Income and Wealth, 56, 483-497. https://doi.org/10.1111/j.1475-4991.2009.00375.x

International Wellbeing Group. (2013). Personal Wellbeing Index. [5 Ed.]. Melbourne: Australian Centre on Quality of Life/Deakin University. Available from http://www.acqol. com.au/instruments\#measures

Jacobs, R., Smith, P. \& Goddard, M. (2004). Measuring performance: an examination of composite performance indicators. [CHE Technical Paper Series 29]. York: Centre for Health Economics. Available from https://www.york.ac.uk/che/pdf/tp29.pdf

Kasparian, J. \& Rolland, A. (2012). OECD's Better life index: can any country be well ranked? Journal of Applied Statistics, 39(10), 1-8. https://doi.org/10.1080/02664763.2012.706265

Kelley, A. (Dec. 1, 2012). Gross National Happiness in Bhutan: The Big Idea from a Tiny State That Could Change the World. theguardian. Available: http://www.theguardian. com/world/2012/dec/01/bhutanwealth-happinesscounts 
Kovacevic, M. (2011). Review of HDI Critiques and Potential Improvements. The Human Development Research Paper, HDRP 2010/33. Vienna: United Nations Development Programme (UNDP). Available: http://hdr.undp.org/en/content/review-hdi-critiques-and-potential-improvements

Layard, R. (2010). Measuring subjective well-being. Science, 327, 534-535. https://oi. org/10.1126/science.1186315

Lee, J. A. \& Souter, G. (2009). Is Schwartz's Value Survey an Interval Scale and Does it Really Matter? Journal of Cross-Cultural Psychology, 42(1), 76-86. https://doi. org/10.1177/0022022109348920

Lim, H.-E. (2008). The Use of Different Happiness Rating Scales: Bias and Comparison Problem? Social Indicators Research, 87, 259-267. https://doi.org/10.1007/s11205-007-9171-x

Linton, M.-J., Dieppe, P. \& Medina-Lara, A. (2016). Review of 99 self-report measures for assessing well-being in adults: Exploring dimensions of well-being and developments over time. BMJ Open, 6(7), 1-16. http://dx.doi.org/10.1136/bmjopen-2015-010641

Mazziotta, M. \& Pareto, A. (settembre 2007). Un indicatore sintetico di dotazione infrastrutturale: il metodo dellepenalità per coefficiente di variazione. In: Atti della XXVIII Conferenza Italiana di Scienze Regionali. AISRe, Bolzano, Italia. Recuperato da https://aisre. it/images/old_papers/Mazziotta-Pareto.pdf

Michalos, A., Smale, B., Labonté, R., Muharjarine, N., Scott, K., Moore, K., Swystun, L., Holden, B., Bernardin, H., Dunning, B., Graham, P., Guhn, M., Gadermann, A.M., Zumbo, B.D., Morgan, A., Brooker, A.-S. \& Hyman, I. (2011). The Canadian Index of Wellbeing. [Technical Report 1.0]. Waterloo: CIW. Available from https://uwaterloo.ca/canadian-index-wellbeing/sites/ca.canadian-index-wellbeing/files/uploads/files/Canadian_Index_of_ Wellbeing-TechnicalPaper-FINAL.pdf

Mikulić, J., Kožić, I. \& Krešić, D. (2015). Weighting indicators of tourism sustainability: A critical note. Ecological Indicators, 48, 312-314. https://oi.org/10.1016/j.ecolind.2014.08.026

Mizobuchi, H. (2014). Measuring world better life frontier: a composite indicator for OECD better life index. Social Indicators Research, 118(3), 987-1007. https://doi.org/10.1007/ s11205-013-0457-x

OECD. (2008). Handbook on Constructing Composite Indicators. Methodology and User Guide. Paris: OECD. Available: https://www.oecd.org/els/soc/handbookonconstructingcompositeindicatorsmethodologyanduserguide.htm

Pinar, M. (2019). Multidimensional Wellbeing and Inequality Across the European Regions with Alternative Interactions Between the Wellbeing Dimensions. Social Indicators Research, 144, 31-72. https://oi.org/10.1007/s11205-018-2047-4

Preston, C. C. \& Colman, A. M. (2000). Optimal number of response categories in rating scales: reliability, validity, discriminating power, and respondent preferences. Acta Psychologica, 104, 1-15. https://doi.org/10.1016/S0001-6918(99)00050-5

Ranis, G., Stewart, F. \& Samman, E. (2006). Human Development: Beyond the Human Development Index. Journal of Human Development, 7(3), 323-358. https://doi. org/10.1080/14649880600815917

Rao, C. R. (1973). Linear Statistical Inference and its Application. [2 Ed.]. New Delhi: Wiley. Rath, T. \& Harter, J. (2010). The economics of wellbeing. Washington, DC: Gallup Press. Available: https://www.gallup.com/services/177050/economics-wellbeing.aspx 
Ray, A. K. (2008). Measurement of social development: An international comparison. Social Indicators Research, 86(1), 1-46. https://oi.org/10.1007/s11205-007-9097-3

Ryff, C. D. \& Keyes, C. L. M. (1995). The structure of psychological well-being revisited. Journal of Personality and Social Psychology, 69(4), 719-727. https://doi.org/10.1037/00223514.69.4.719

Saisana, M. \& Tarantola, S. (2002). State-of-the-art Report on Current Methodologies and Practices for Composite Indicator Development. [EUR20408 EN]. Ispra: European Commission/Joint Research Centre. http://dx.doi.org/10.13140/RG.2.1.1505.1762

Sen, A. K. (1985). Commodities and capabilities. Amsterdam: North-Holland.

Seth, S. \& Villar, A. (2017). Measuring human development and human deprivations. [OPHI Working Paper 110]. Oxford: University of Oxford. Available from https://www.ophi.org. uk/wp-content/uploads/OPHIWP110.pdf

Sharpe, A. (2004). Literature review of frameworks for macro-indicators. [CSLS Research Report 2004-03]. Ottawa: Centre for the Study of Living Standards. Available from https:// core.ac.uk/download/pdf/7033316.pdf

SPRG. (2001). Report of the Scientific Peer Review Group on Health Systems Performance Assessment. [Scientific Peer Review Group (SPRG)]. Geneva: WHO. Available: https:// apps.who.int/iris/handle/10665/68352

Stiglitz, J. E., Sen, A. \& Fitoussi, J.-P. (2009). Report by the Commission on the Measurement of Economic Performance and Social Progress. París: CMEPSP. Available from https:// ec.europa.eu/eurostat/documents/8131721/8131772/Stiglitz-Sen-Fitoussi-Commission-report.pdf

UNDP. (2007). Fighting climate change: Human solidarity in a divided world. [Human development report 2007/2008]. New York: Palgrave Macmillan. Available: http://hdr.undp.org/ en/content/human-development-report-20078

Venkatesh, A. K. \& Bernheim, S. M. (Dir.) (2016). Overall hospital quality star ratings on hospital compare. [Methodology report (v2.0)]. New Haven: YNHHSC/CORE. Available from https://cpb-us-w2.wpmucdn.com/u.osu.edu/dist/c/28860/files/2016/08/Star_Rtngs_ CompMthdlgy_052016-148w094.pdf

Ware Jr, J. E. \& Sherbourne, C. D. (1992). The MOS 36-item short-form health survey (SF36). I. Conceptual framework and item selection. Medical Care, 30(6), 473-483. Available: https://pubmed.ncbi.nlm.nih.gov/1593914/

Yang, L. (2018). Measuring individual well-being: A multidimensional index integrating subjective well-being and preferences. Journal of Human Development and Capabilities, 19(4), 456-476. https://doi.org/10.1080/19452829.2018.1474859

Zarzosa, P. Z. \& Somarriba, N. (2012). An Assessment of Social Welfare in Spain: Territorial Analysis Using a Synthetic Welfare Indicator. Social Indicators Research, 111(1), 1-23. https://doi.org/10.1007/s11205-012-0005-0

Satyendra Nath Chakrabartty. M. Stat. from Indian Statistical Institute. Has taught Post Graduate courses at the same institute, University of Calcutta, Galgotias Business School, etc. He has over 65 publications to his credit. He retired from the position of Director (Kolkata Campus, Indian Maritime University). His previous assignment was Consultant( Indian Ports Association, New Delhi). https:/orcid.org/0000-0002-7687-5044 